\title{
Article \\ Identification of Druggable Genes for Asthma by Integrated Genomic Network Analysis
}

\author{
Wirawan Adikusuma ${ }^{1,2} \mathbb{D}^{\mathbb{D}}$, Wan-Hsuan Chou ${ }^{1} \mathbb{D}$, Min-Rou Lin $^{1}{ }^{1}$, Jafit Ting ${ }^{1} \mathbb{D}$, Lalu Muhammad Irham ${ }^{3}$, \\ Dyah Aryani Perwitasari ${ }^{3}\left(\mathbb{D}\right.$, Wei-Pin Chang ${ }^{4, *}$ and Wei-Chiao Chang $1,5,6,7,8, *$
}

1 Department of Clinical Pharmacy, School of Pharmacy, Taipei Medical University, Taipei 11031, Taiwan; adikusuma28@gmail.com (W.A.); ocean.chou@tmu.edu.tw (W.-H.C.); jennlin@tmu.edu.tw (M.-R.L.); jkt5265@tmu.edu.tw (J.T.)

2 Department of Pharmacy, Faculty of Health Science, University of Muhammadiyah Mataram, Mataram 83127, Indonesia

3 Faculty of Pharmacy, University of Ahmad Dahlan, Yogyakarta 55164, Indonesia; lalu.irham@pharm.uad.ac.id (L.M.I.); dyah.perwitasari@pharm.uad.ac.id (D.A.P.)

4 School of Health Care Administration, College of Management, Taipei Medical University, Taipei 11031, Taiwan

5 TMU Research Center of Cancer Translational Medicine, Taipei 11031, Taiwan

6 Department of Pharmacy, Wan Fang Hospital, Taipei Medical University, Taipei 11696, Taiwan

7 Integrative Research Center for Critical Care, Wan Fang Hospital, Taipei Medical University, Taipei 11696, Taiwan

8 Department of Pharmacology, National Defense Medical Center, Taipei 11490, Taiwan

* Correspondence: wpchang@tmu.edu.tw (W.-P.C.); wcc@tmu.edu.tw (W.-C.C.)

check for updates

Citation: Adikusuma, W.; Chou, W.-H.; Lin, M.-R.; Ting, J.; Irham, L.M.; Perwitasari, D.A.; Chang, W.-P.; Chang, W.-C. Identification of Druggable Genes for Asthma by Integrated Genomic Network Analysis. Biomedicines 2022, 10, 113. https://doi.org/10.3390/ biomedicines10010113

Academic Editor: Jun Lu

Received: 1 December 2021

Accepted: 24 December 2021

Published: 6 January 2022

Publisher's Note: MDPI stays neutral with regard to jurisdictional claims in published maps and institutional affiliations.

Copyright: (C) 2022 by the authors. Licensee MDPI, Basel, Switzerland. This article is an open access article distributed under the terms and conditions of the Creative Commons Attribution (CC BY) license (https:// creativecommons.org/licenses/by/ $4.0 /)$.

\begin{abstract}
Asthma is a common and heterogeneous disease characterized by chronic airway inflammation. Currently, the two main types of asthma medicines are inhaled corticosteroids and long-acting $\beta 2$-adrenoceptor agonists (LABAs). In addition, biological drugs provide another therapeutic option, especially for patients with severe asthma. However, these drugs were less effective in preventing severe asthma exacerbation, and other drug options are still limited. Herein, we extracted asthma-associated single nucleotide polymorphisms (SNPs) from the genome-wide association studies (GWAS) and phenome-wide association studies (PheWAS) catalog and prioritized candidate genes through five functional annotations. Genes enriched in more than two categories were defined as "biological asthma risk genes." Then, DrugBank was used to match target genes with FDA-approved medications and identify candidate drugs for asthma. We discovered 139 biological asthma risk genes and identified 64 drugs targeting 22 of these genes. Seven of them were approved for asthma, including reslizumab, mepolizumab, theophylline, dyphylline, aminophylline, oxtriphylline, and enprofylline. We also found 17 drugs with clinical or preclinical evidence in treating asthma. In addition, eleven of the 40 candidate drugs were further identified as promising asthma therapy. Noteworthy, IL6R is considered a target for asthma drug repurposing based on its high target scores. Through in silico drug repurposing approach, we identified sarilumab and satralizumab as the most promising drug for asthma treatment.
\end{abstract}

Keywords: asthma; bioinformatic; drug repositioning; genome-wide association study; phenome-wide association study

\section{Introduction}

Asthma is a prevalent chronic respiratory disease that can adversely influence patients' quality of life of all ages and genders. Patients usually suffer from repeated episodes of wheezing, shortness of breath, tightness of the chest, and coughing [1,2]. Asthma, a heterogeneous disease, is classified into different clinical phenotypes such as allergic asthma, non-allergic asthma, adult-onset asthma, asthma with persistent airflow limitation, and asthma with obesity [3]. It is estimated that approximately 339 million people worldwide 
have asthma, with an estimated prevalence rate of $1-18 \%$. In addition to the rising prevalence, morbidity and mortality rates have increased over the past few decades $[1,4,5]$. The increasing number of asthma patients is a burden to medical investments and represents increased care costs for families and communities [5]. The combination of genetic and environmental factors is widely thought to play a crucial role in the pathogenesis and treatment efficacy of asthma [6,7]. Studies of gene-environmental interactions may help elucidate disease mechanisms and classify particular genes or exposures in the same pathway [8].

The main goal of asthma treatments is to control the symptoms properly and prevent exacerbation. Two drugs are generally the leading choices for treating asthma: inhaled corticosteroids and long-acting $\beta_{2}$-adrenoceptor agonists (LABAs). Severe asthma patients need add-on therapies, such as biological drugs (Monoclonal antibodies) that target specific molecular pathways [3,9]. However, these drugs do not prevent severe disease exacerbation in a significant proportion of patients [10]. This indicates a need to develop novel antiasthma therapies. The development of new small-molecule drugs is a risky undertaking that costs hundreds of millions of dollars and needs years of research and clinical trials. Unfortunately, many drugs failed during safety testing in Phase I trials and were not able to move forward in the clinical trial process [11]. With the rapid development of bioinformatics knowledge and big biological data, drug repositioning strategies can be used to seek new indications for approved drugs [11-13]. It can significantly reduce the time, costs, and risks of the drug development process [14,15], and serves as a solution for the pharmaceutical industry to improve their profits and overcome future medical challenges.

New drug discovery is a challenging process. Several methods can be used to find new indications for existing drugs, such as knowledge-based, activity-based, and in silico-based drug repurposing [16]. In the present study, we performed in silico drug repurposing with the integration of both gene network and bioinformatic analytic approaches to find promising candidate drugs for asthma therapy.

\section{Materials and Methods}

\subsection{Study Design}

An overview of the research design is shown in Figure 1. We acquired asthmaassociated single-nucleotide polymorphisms (SNPs) through genome-wide association studies (GWASs) [17] and Phenome-wide association studies (PheWAS) Catalog [18] on 8 May 8 2019. GWAS catalog is one of the largest resources available online (https: //www.ebi.ac.uk/gwas/, 8 May 2019). The purpose of GWAS is to decipher associations between common genetic variants and diseases or traits. In the "opposite" orientation of GWAS, PheWAS investigates the correlation between diseases or traits and particular genetic variants [19]. Next, HaploReg v4.1 (Massachusetts Institute of Technology, 77 Massachusetts Avenue, Cambridge, MA, USA) [20] extended the asthma-associated SNPs to identify asthma risk genes with criterion $r^{2}>0.8$ in the Asian population. Five functional annotation criteria have been used to give priority to these genes. We prioritized genes as "biological asthma risk genes" if they were annotated to meet more than or equal to two criteria (score $\geq 2$ ). Then, we mapped biological asthma risk genes based on DrugBank [21] to find candidate drugs. ClinicalTrial.gov (https: / clinicaltrials.gov/) and PubMed literature reviews accessed on 26 October 2021 were used to identify the most promising drug for asthma.

\subsection{Biological Asthma Risk Genes}

Biological asthma risk genes were obtained based on the five functional annotations that met two or more of the requirements (i.e., had a score of $\geq 2$ ). We adopted the scoring system from a previous study by Okada et al., which predicted the candidate drugs for rheumatoid arthritis [22]. Each gene in the risk loci for asthma was scored according to the following five criteria: (1) Missense: genes containing asthma risk SNPs with linkage disequilibrium $\left(r^{2}>0.80\right)$ and were annotated as missense mutations in HaploReg v4.1; (2) Cis-expression quantitative trait locus (Cis-eQTL): genes containing asthma risk SNPs 
with significant cis-eQTL effect in the lung; (3) Knockout mouse phenotype (KO mice): genes with a significance of False Discovery Rate (FDR) $q<0.05$ in the over-representation analysis (ORA) using Mammalian Phenotype Ontology (MP) from WebGestalt (2019) [23]; (4) Protein-protein interactions (PPIs): genes were prioritized by biological process Gene Ontology (GO) categories in WebGestalt 2019 [23]. Those with an FDR $q<0.05$ were considered significant, and (5) Molecular pathway: genes were prioritized using the Kyoto Encyclopedia of Genes and Genomes (KEGG), an online biochemical route database from WebGestalt 2019 [23]. Genes involved in significantly enriched pathways (FDR $q<0.05$ ) were assigned one point. Each gene was scored based on the number of matched criteria (scores ranged from 0 to 5 for each gene).

Asthma risk genes
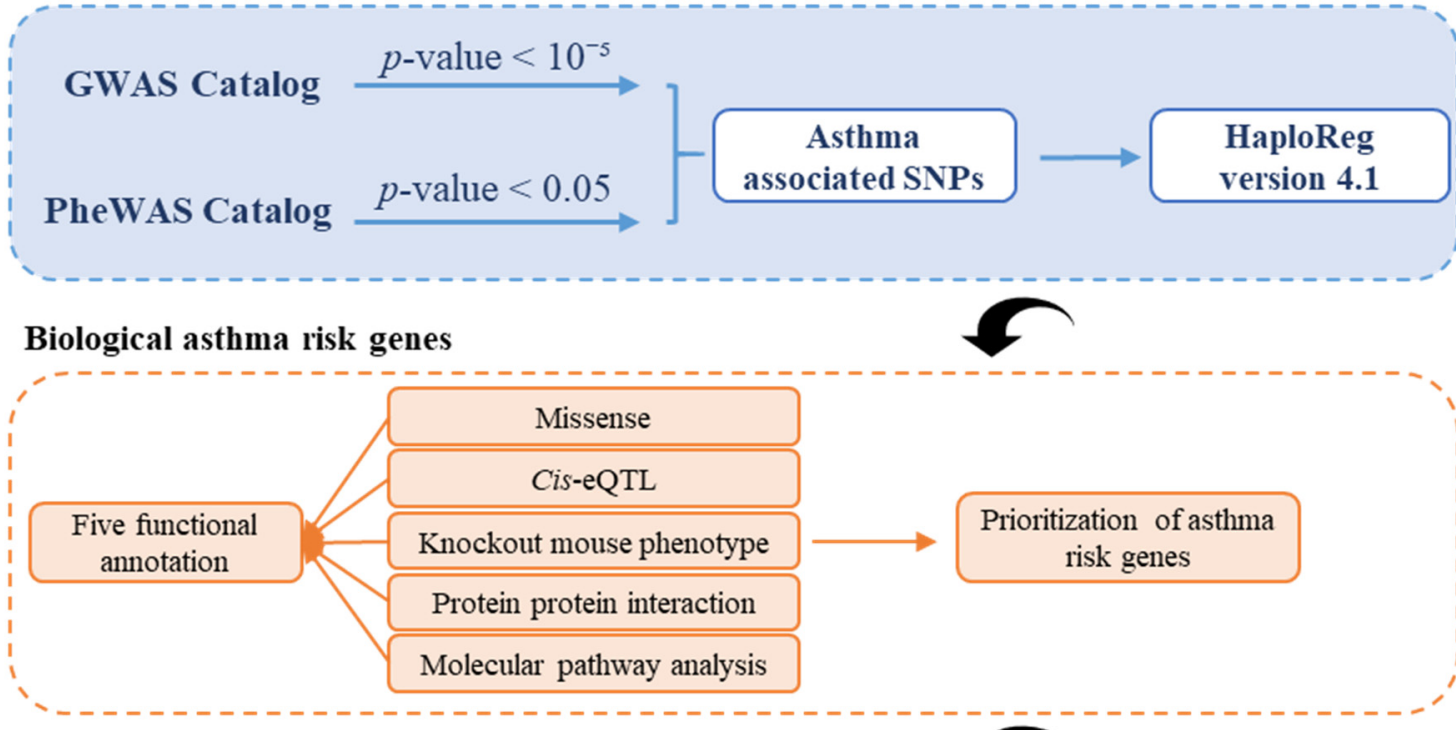

Drug target mapping
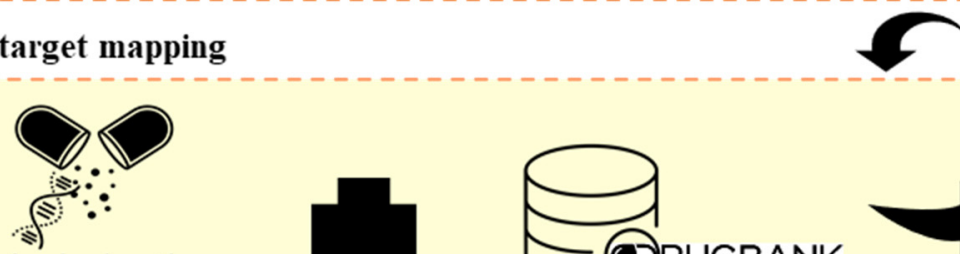

Biological asthma
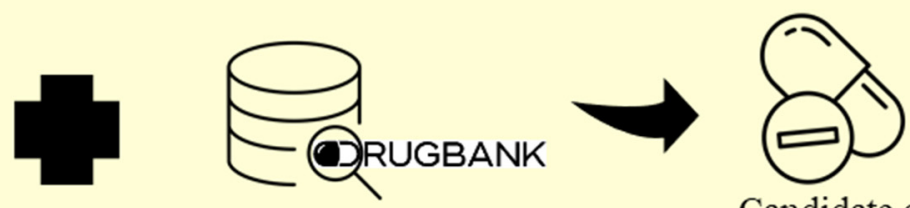

risk genes

\section{Candidate drug}

Drug repositioning

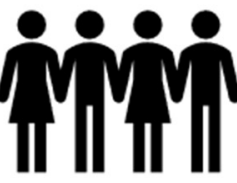

08080808

ClinicalTrial.gov

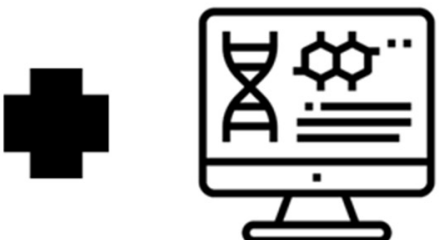

PubMed literature review

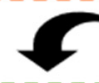

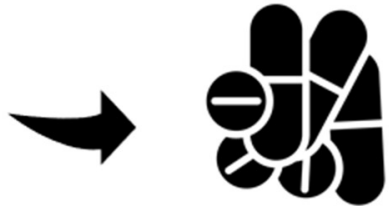

Promising drugs for asthma

Figure 1. Study design of the drug repurposing approach to identify promising drugs for asthma. Asthma-associated SNPs were identified through GWAS and PheWAS Catalog. Next, the asthmaassociated SNPs were extended by HaploReg v4.1 to identify asthma risk genes. Five criteria of functional annotation were used to prioritize candidate genes. Candidate genes were linked to drugs through the DrugBank database. Furthermore, we used ClinicalTrial.gov and PubMed literature review to find a promising repurposed drug for asthma. 


\subsection{Drug Mining and Prioritization}

In this step, we mapped biological asthma risk genes to DrugBank (data released on 3 January 2021) to find candidate drugs for asthma. DrugBank is an online database that provides information about drugs and gene targets as a bioinformatics and cheminformatics resource for drug discovery in clinical medicine communities. The DrugBank can be used for in silico drug target discovery, drug design, drug docking or screening, drug metabolism prediction, drug interaction prediction, and general pharmaceutical education [21]. Several parameters were used to query the databases, such as drugs with pharmacological activity, human effectiveness, approved annotations, clinical trials, or experimental drugs. Furthermore, all drugs were confirmed by ClinicalTrial.gov (https:/ / clinicaltrials.gov/; accessed on 26 October 2021) to verify if each drug is under clinical investigation for asthma or other diseases.

\subsection{Statistical Analysis}

In this study, all analytic workflows were performed on RStudio version 4.0.3 (RStudio, 250 Northern Ave, Boston, MA 02210). Missense and Cis-expression quantitative trait locus (Cis-eQTL) were performed in R using the haploR package [24]. Over-representation analysis (ORA), including Knockout Mouse Phenotype, PPI network, and Molecular Pathway, were performed using the WebGestalt R package [25].

\section{Results}

\subsection{Identification of Asthma Associated SNP}

A total of 969 asthma-associated SNPs were extracted, including 658 from the GWAS catalog $\left(p\right.$-value $\left.<10^{-5}\right)$ and 336 from the PheWAS catalog ( $p$-value $\left.<0.05\right)$ (Table S1). Subsequently, based on the characteristic of $r^{2}>0.8$ used in Asian populations, we extended the number of SNPs by HaploReg v4.1 and obtained 1047 asthma risk genes (Table S2).

\subsection{Gene-Based Prioritization from Functional Annotation}

We utilized five functional annotations to determine which genes have priority for drug discovery. The scoring results were as follow: (1) genes include asthma risk missense variant $(n=66)$; (2) genes with Cis-eQTL effect $(n=72)$; (3) genes prioritized by KO mice $(n=84)$; (4) genes prioritized by PPIs $(n=284)$; and (5) genes prioritized by a molecular pathway $(n=88)$. Finally, a total of 139 biological asthma risk gene fulfilled the criteria with a score $\geq 2$. We evaluated the gene scores to provide empirical evidence of the pipeline. Our result showed that the top five genes have a score higher than 3, including IL1RL1, FCER1G, IL6R, IL13, and HLA-DQB1 (Figure 2A; Table S3). The distribution score of each criterion is shown in Figure 2B,C. Furthermore, we found that these five criteria showed a low positive correlation $(r<0.4)$ to each other (Figure 2D).

\subsection{Integrative Analysis for Drug Repositioning}

To identify the candidate drugs for asthma, we mapped biological asthma risk genes to drugs in DrugBank. We evaluated whether genes from the biologically risky gene profiles were pharmacologically therapeutic targets of approved drugs. A total of 64 drugs were identified, which targeted 22 asthma risk genes. Thus, these drugs are considered as candidate drugs for asthma therapy (Table S4). Among these 64 drugs, seven were approved for asthma; twelve were under clinical investigation for asthma; five were supported by preclinical in vivo or in vitro asthma models, and 40 were novel drugs that have not been reported to treat asthma. First, we focused on drugs supported by FDA approval, clinical studies, and preclinical evidence. A total of eight genes were targeted by these drugs, including IL5, HMGCR, PIK3CD, CD86, BCR, NOS1, IL6R, and ADORA1 (Figure 3). Besides, a list of 17 drugs with clinical and preclinical data is shown in Table 1. Thus, these genes are considered promising targets for asthma. Finally, by matching these eight genes to the 40 novel drugs, we identified eleven drugs (idelalisib, copanlisib, cerivastatin, sarilumab, satralizumab, bosutinib, ponatinib, methylene blue, antithymocyte 
immunoglobulin (rabbit), and istradefylline) matching with seven genes that might be repurposed for asthma (Figure 4).

\begin{tabular}{|c|c|c|c|c|c|c|c|}
\hline \multirow[b]{2}{*}{ GENCODE_id } & \multirow[b]{2}{*}{ GENCODE_name } & \multirow[b]{2}{*}{ Score } & \multicolumn{5}{|c|}{$\begin{array}{l}\text { Biological as thma } \\
\text { lisk genes criteria }\end{array}$} \\
\hline & & & 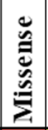 & 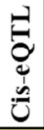 & $\begin{array}{c}\stackrel{\mathscr{\Xi}}{\Xi} \\
\stackrel{\Xi}{\prime} \\
O^{\prime}\end{array}$ & $\overrightarrow{\mathbf{a}}$ & بئ \\
\hline ENSG00000115602 & ILIRLI & 5 & & & & & \\
\hline ENSG00000158869 & FCERIG & 4 & & & & & \\
\hline ENSG00000160712 & $I L 6 R$ & 4 & & & & & \\
\hline ENSG00000169194 & IL13 & 4 & & & & & \\
\hline ENSG00000179344 & $H L A-D Q B 1$ & 4 & & & & & \\
\hline ENSG00000020633 & RUNX3 & 3 & & & & & \\
\hline ENSG00000069667 & RORA & 3 & & & & & \\
\hline ENSG00000074047 & GLI2 & 3 & & & & & \\
\hline ENSG00000084674 & $A P O B$ & 3 & & & & & \\
\hline ENSG00000087088 & $B A X$ & 3 & & & & & \\
\hline ENSG00000088888 & MAVS & 3 & & & & & \\
\hline ENSG00000090339 & ICAMI & 3 & & & & & \\
\hline ENSG00000101017 & $C D 40$ & 3 & & & & & \\
\hline ENSG00000104901 & DKKLI & 3 & & & & & \\
\hline ENSG00000106571 & GLI3 & 3 & & & & & \\
\hline ENSG00000107485 & GATA3 & 3 & & & & & \\
\hline ENSG00000107957 & $S H 3 P X D 2 A$ & 3 & & & & & \\
\hline ENSG00000108379 & WNT3 & 3 & & & & & \\
\hline ENSG00000109471 & $I L 2$ & 3 & & & & & \\
\hline ENSG00000111335 & $O A S 2$ & 3 & & & & & \\
\hline ENSG00000112486 & CCR6 & 3 & & & & & \\
\hline ENSG00000112964 & $G H R$ & 3 & & & & & \\
\hline
\end{tabular}

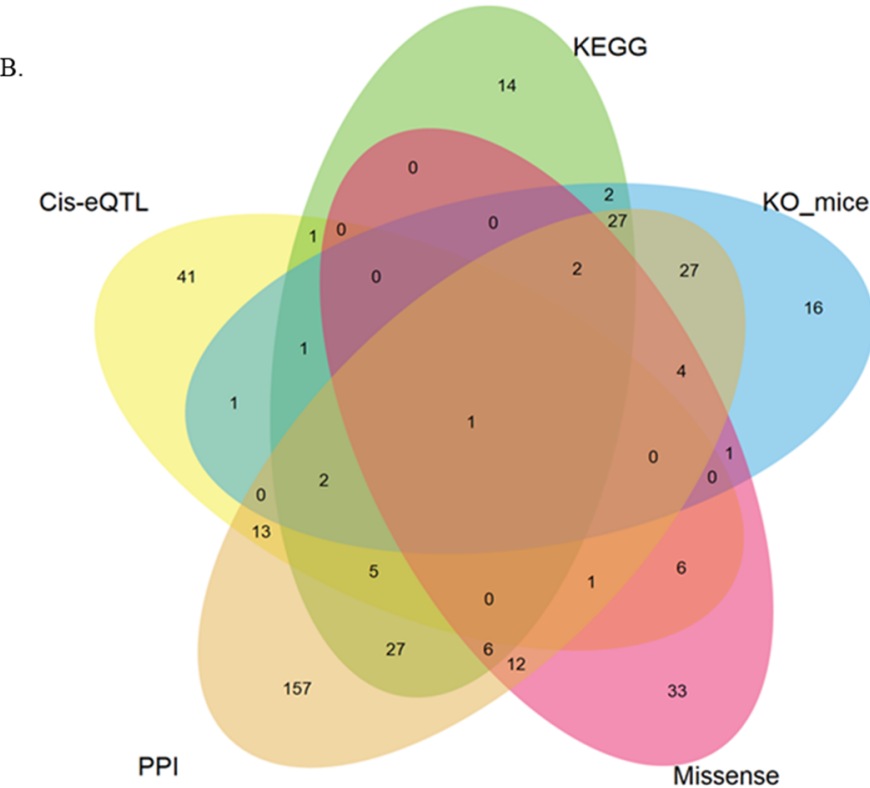

\section{Biological criteria}

C

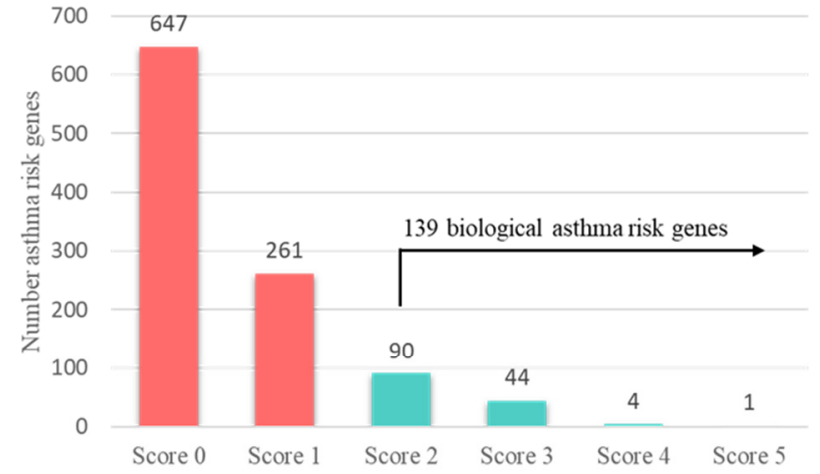

D.

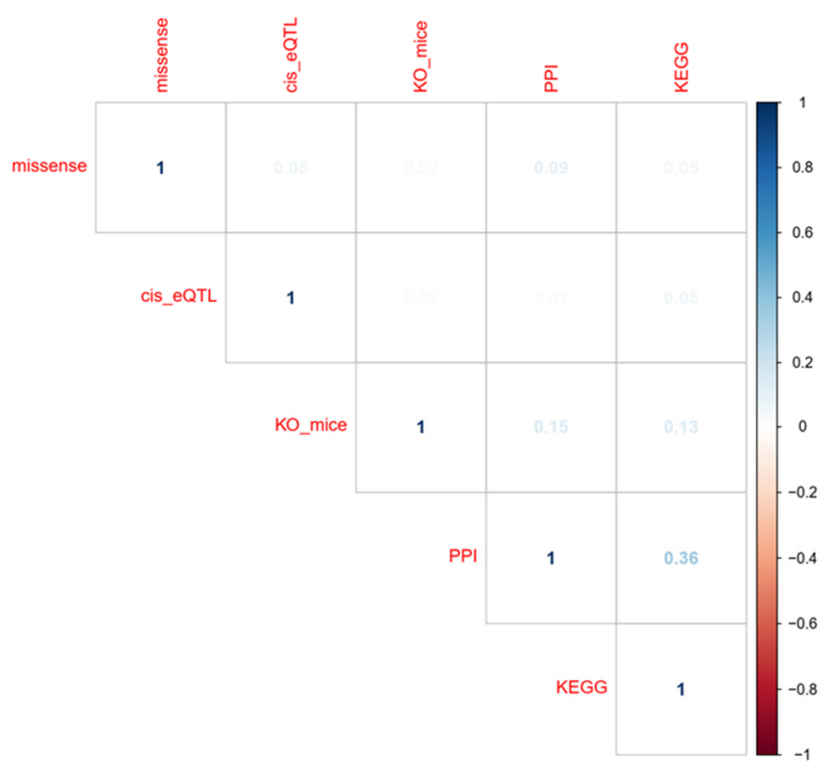

Figure 2. Prioritization of biological candidate gene from asthma risk loci. (A) Summary scores derived from 5 criteria are shown. The boxes are filled with different colors to distinguish each functional annotation. Filled boxes indicate fulfilled criteria. Gene with a score $\geq 2$ was defined as "biological asthma risk genes." For complete information, see Table S3. (B) Venn diagram shows the prioritization criteria of the biological candidate gene from asthma risk loci. (C) Histogram distribution of gene scores. The figure shows 139 genes with total scores $\geq 2$. (D) Correlogram indicates the pairwise Phi correlation coefficient between the five criteria. The blue color denotes a positive correlation, while the red color denotes a negative correlation. 


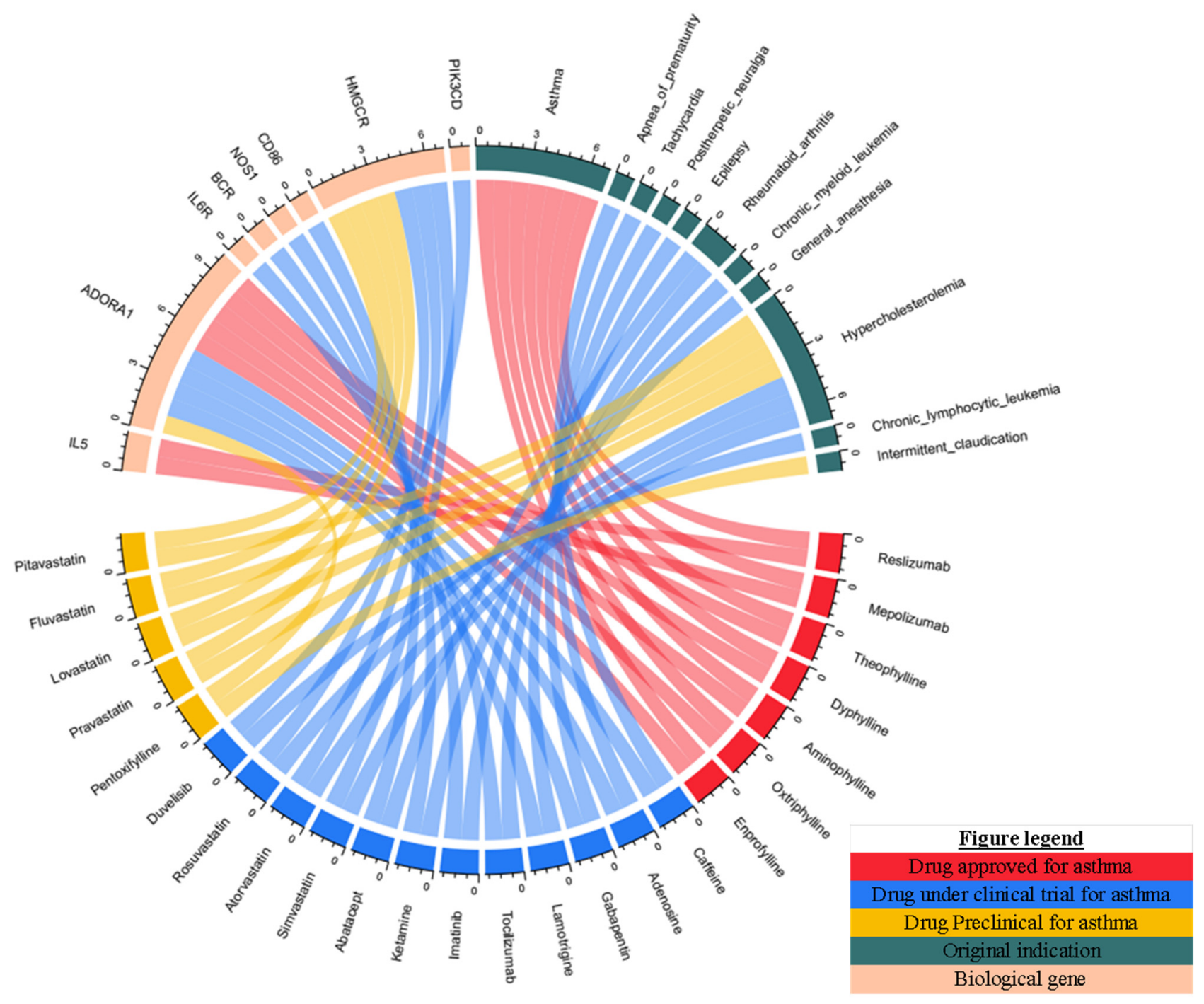

Figure 3. Chord diagram of the connections among biological gene, drug target, and indications identified by clinical trial and PubMed literature review.

Table 1. Asthma candidate drugs supported by clinical trials and preclinical evidence.

\begin{tabular}{|c|c|c|c|c|c|}
\hline Drug Candidate & Gene Target & Drug Action & Current Drug Indication & $\begin{array}{c}\text { Phase of } \\
\text { Development }\end{array}$ & $\begin{array}{l}\text { N.C.T. Number/ } \\
\text { PubMed ID }\end{array}$ \\
\hline Gabapentin & ADORA1 & Agonist & Postherpetic neuralgia & Phase IV & NCT00153283 \\
\hline Lamotrigine & ADORA1 & Inhibitor & Epilepsy & Phase IV & NCT00153244 \\
\hline Simvastatin & $H M G C R$ & Inhibitor & Hypercholesterolemia & Phase III & NCT01266434 \\
\hline Ketamine & NOS1 & Inhibitor & General anaesthesia & Phase III & NCT03338205 \\
\hline Atorvastatin & HMGCR & Inhibitor & Hypercholesterolemia & Phases II/III & NCT00126048 \\
\hline Imatinib & $B C R$ & Inhibitor & Chronic myelogenous leukaemia & Phase II & NCT01097694 \\
\hline Abatacept & CD86 & Antagonist & Rheumatoid arthritis & Phase II & NCT00784459 \\
\hline Duvelisib & РIКЗСС & Inhibitor & Small lymphocytic lymphoma & Phase II & NCT01653756 \\
\hline Adenosine & ADORA1 & Agonist & Tachycardia & Phase II & NCT01006655 \\
\hline Rosuvastatin & $H M G C R$ & Inhibitor & Hypercholesterolemia & Phase I & NCT01411111 \\
\hline Tocilizumab & $I L 6 R$ & Inhibitor & Rheumatoid arthritis & Phases I/II & $\begin{array}{c}\text { ACTRN12614000123640, } \\
25930193,30885880\end{array}$ \\
\hline Caffein & ADORA1 & Inhibitor & Apnea of prematurity & NA & NCT01057875 \\
\hline Pentoxifylline* & ADORA1 & & Intermittent claudication & - & 19905913 \\
\hline Pitavastatin * & HMGCR & Inhibitor & Hypercholesterolemia & - & 28729731 \\
\hline Pravastatin * & HMGCR & Inhibitor & Hypercholesterolemia & - & 18835962 \\
\hline Lovastatin * & HMGCR & Inhibitor & Hypercholesterolemia & - & 25374755 \\
\hline Fluvastatin * & HMGCR & Inhibitor & Hypercholesterolemia & - & 16630152 \\
\hline
\end{tabular}

* Represents preclinical in vivo or in vitro; NA, not available. 


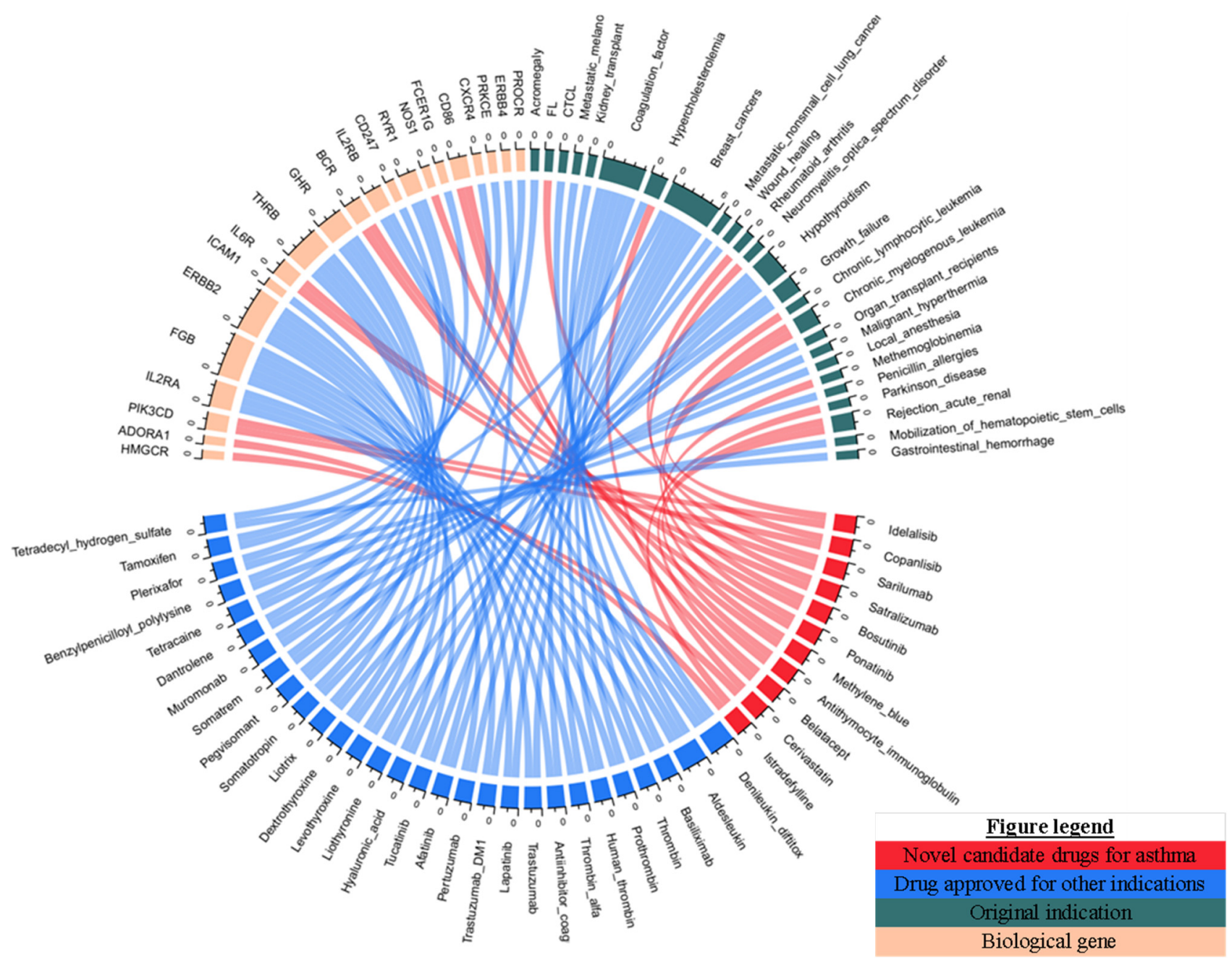

Figure 4. Chord diagram of the connections between biological genes with promising anti-asthma drugs. Connections with biological genes investigated in clinical and preclinical evidence are highlighted in red color.

\section{Discussion}

In this study, GWAS and PheWAS databases were used to extract information from asthma risk loci that could guide the drug repurposing process. One hundred thirty-nine genes were classified as biological asthma risk genes using five biological criteria. Through DrugBank, we identified 64 drugs targeting 22 genes, of which seven drugs were approved for asthma, such as mepolizumab, reslizumab, theophylline, dyphylline, aminophylline, oxtriphylline, and enprofylline. Besides, 17 drugs with clinical and preclinical evidence were found useful for asthma therapy. Therefore, our result suggests that the combination of GWAS, PheWAS, and in silico approach is valuable to provide scientific evidence for asthma drug discovery.

Among the seven promising target genes for asthma, we screened out IL6R as a highly promising target for treatment of asthma since the gene also acquired a high systemic score in functional annotations. The role of IL6R in asthma has been supported by preclinical and clinical trial evidence. IL-6 signaling was implied by an animal, genetic association, and clinical studies in allergic asthma. IL-6 trans-signaling has a pathogenic role in asthma severity-related airways. The IL-6 trans-signaling large subset was overrepresented by frequent exacerbations, blood eosinophilia, and submucosal $\mathrm{T}$ cell and macrophage infiltration [26]. When $I L-6$ binds to the $I L-6 R$, it does not induce a signaling cascade. However, it is associated with the gp130 signal transducer protein, which triggers the activation of the specific members of the JAK family of tyrosine kinase (JAK1, JAK2, JAK3, and Tyk2), 
leading to phosphorylation and activation of the major transcriptional factor controlled by $I L-6$ and STAT3 [27,28]. Furthermore, the secretion of $I L-6$ also induced the C/EBP $\beta$ transcription factor through the $M A P K$ pathway [29]. Recent mouse studies, along with the surprising GWAS results demonstrating a genetic link between $I L-6 R$ and human asthma, indicated that $I L-6$ (or $I L-6 R$ ) is a priority for asthma treatment [30,31]. Anti-IL-6R mAb that blocks both mIL-6R and sIL-6R involves activating IL-6 trans-signaling to prevent allergeninduced asthma exacerbations [32,33]. This study found three anti-IL6R mAb, including tocilizumab, sarilumab, and satralizumab. One of these drugs (tocilizumab) has been in clinical trials for asthma (Trial registered in the Australian New Zealand Clinical Trials Registry, number ACTRN12614000123640). By targeting IL6R, sarilumab and satralizumab could become novel candidate drugs for asthma treatment options.

Among the target identified, the roles of HMGCR and ADORA1 as implicated in asthma are supported by clinical and preclinical evidence. HMGCR plays an essential role in cholesterol and isoprenoids biosynthesis in the mevalonate (MA) pathway. Isoprenoid was associated with asthma-related processes and respiratory disorders, including allergic eosinophilic inflammation [34-37]. Allergic asthma significantly increased the HMGCR expression in the liver, and increased HMGCR expression indicates increased cholesterol biosynthesis [38]. Statin drugs, which have been used clinically for hyperlipidemia and cardiovascular diseases for decades, directly inhibit HMGCR [35]. In this study, we identified eight statin drugs targeting HMGCR. Among them, three drugs (simvastatin, NCT0126643; atorvastatin, NCT00126048; rosuvastatin, NCT00463827) are under clinical trial investigation; four drugs (pitavastatin [39], pravastatin [40], lovastatin [41], and fluvastatin [42]) are supported by in vivo or in vitro preclinical data for asthma. Since several in vivo or in vitro studies showed that statin drugs could reduce inflammatory airways; cerivastatin may become a promising candidate for asthma treatment by targeting HMGCR [43,44]. The adenosine receptors ( $A D O R A 1, A D O R A 2 A, A D O R A 2 B$, and $A D O R A 3$ ) have a promising therapeutic role in asthma and chronic obstructive pulmonary disease (COPD) [45]. By activating antagonists $A D O R A 1 / A D O R A 2 B$, adenosine mediates bronchoconstriction and mucin formation and increases endothelial cell permeability in preclinical studies [46]. Several drugs that target $A D O R A 1$ were in preclinical or clinical trials for asthma, as shown in Table 1. In particular, we identified istradefylline as a novel candidate drug for asthma.

Additionally, our bioinformatic networking analysis also showed that CD86 and NOS1 are promising targets for asthma drug repurposing. CD86 is associated with three drugs (abatacept, belatacept, and antithymocyte immunoglobulin (rabbit)). One of these drugs (abatacept) has completed clinical trial phase II (NCT00784459). The expression of CD86 in B cells was significantly increased in asthma patients. Blocking CD86 effectively inhibits allergic reactions by decreasing Th2 cytokines production $[47,48]$. Furthermore, a previous study showed that NOS1 plays a significant role in asthmatic children [49]. Several drugs were linked to NOS1, such as ketamine and methylene blue. In clinical trial phase III, ketamine was used as adjuvant therapy in pediatric emergency patients with acute asthma (NCT03338205). The last category of drugs identified in this study were anticancer drugs (bosutinib, ponatinib, idelalisib, and copanlisib), targeting $B C R$ and PIK3CD. Herein, $B C R$ is linked to three drugs such as imatinib, bosutinib, and ponatinib. Among these drugs, only imatinib is under clinical trial for asthma. In a phase II randomized clinical trial for severe refractory asthma, imatinib could reduce hyperresponsiveness to the airway, mast-cell counts, and tryptase release (NCT01097694). Meanwhile, PIK3CD is mapped to three (duvelisib, idelalisib, and copanlisib) types of cancer drugs. Duvelisib is one of the three drugs that have been in a clinical trial for asthma (NCT01653756) and shows good tolerance as reported for each dose variation evaluated [50]. However, anticancer drugs target fast growing cells in the body without considering that the body also contains rapidly dividing non-cancerous cells. These drugs have a narrow therapeutic index, meaning that the doses required to create an anticancer effect and the levels required to produce harmful consequences are similar [51]. Hence, our study did not consider anticancer drugs for asthma drug repurposing due to the high adverse effects. 
Drug repurposing offers various advantages over developing an entirely new drug for a given indication, such as fewer risks, lower cost, and shorter development time [52]. Nevertheless, the approach does not always succeed; one example was a recent case of risankizumab in severe asthma. A phase 2a, placebo-controlled trial (NCT02443298) showed that the repurposed drug might not benefit severe asthma patients [53]. The failure may be due to biological variations of biomarkers, etiology of disease, and clinical phenotypes among patients. The deviations lead to different patterns of treatment response. In this study, we included previous reports of any types of asthma (e.g., chronic obstructive asthma, adult-onset asthma, atopic asthma, childhood-onset asthma), and extracted the asthma-associate genetic variants from GWAS and PheWAS catalogs. Without the further specification of patient subgroups, studies on animal models with different phenotypes and clinical trials are necessary to validate the effectiveness of the candidate drugs in practical usage. This study utilized incorporated genetic data, computational methods, and publicly accessible big data sets to prioritize the best candidate genes and identify new drugs for asthma therapy. However, there are some limitations. First, genes from the GWAS and PheWAS catalogs are not always druggable, and not all gene targets emerge distinct pharmacological activity. Our analysis showed that among 139 biological asthma risk genes, however, only 22 genes are druggable. Second, the therapeutic drugs found in this pipeline have not been validated. Further functional studies and clinical studies are required to determine the possibility of clinical application and implementation in our findings.

\section{Conclusions}

Drug repositioning through in silico methods provides a faster drug discovery process to find novel indications for approved drugs in complex human diseases. Through our pipeline, we identified seven approved drugs, 17 drugs with clinical and preclinical evidence, and 40 novel drugs for asthma. In particular, seven gene targets (HMGCR, ADORA1, IL6R, CD86, BCR, PIK3CD, and NOS1) are prioritized for asthma drug repurposing. These genes were mapped to eleven novel drugs, which is worthy of further investigation. Among these targets, we highly recommend drugs targeting IL6R for asthma repurposing, since the gene had a high systemic score in functional annotations. In summary, our results revealed that the anti-IL6R (Sarilumab and satralizumab) are promising candidates for drug repositioning to asthma therapy. However, it will be helpful to carry out more studies from animal models and clinical trials to determine the mechanisms of anti-IL6R in asthma.

Supplementary Materials: The following supporting information can be downloaded at: https:/ / www.mdpi.com/article/10.3390/biomedicines10010113/s1, Table S1: Summary of asthma-associated SNPs from GWAS and PheWAS catalogs, Table S2: Summary of 1047 asthma risk genes based on linkage disequilibrium $\left(r^{2}>0.8\right)$, Table S3: Summary of 139 biological asthma risk genes, Table S4: Summary of 64 candidate drugs from DrugBank database.

Author Contributions: Conceptualized, conceived, and designed the study: W.A., and W.-C.C. Performed the analysis: W.A. Curated the data: W.A., W.-H.C., M.-R.L., J.T., L.M.I., and W.-C.C. Wrote the original draft: WA. Interpreted the data: W.A., W.-H.C., M.-R.L., J.T., L.M.I., D.A.P., W.-P.C., and W.-C.C. Revised the manuscript: W.A., W.-H.C., M.-R.L., J.T., L.M.I., D.A.P., W.-P.C., and W.-C.C. Provided the funding: W.-P.C. and W.-C.C. All authors have read and agreed to the published version of the manuscript.

Funding: This project was supported by grants from the Ministry of Science and Technology, Taiwan (MOST 110-2628-B-038-020; MOST 110-2314-B-038-161), and Taipei Medical University (109-5807-006-400).

Institutional Review Board Statement: Not applicable.

Informed Consent Statement: Not applicable.

Data Availability Statement: The data presented in this study are available in supplementary material.

Conflicts of Interest: The authors declare that no conflict of interest exists. 


\section{References}

1. Holgate, S.T.; Wenzel, S.; Postma, D.S.; Weiss, S.T.; Renz, H.; Sly, P.D. Asthma. Nat. Rev. Dis. Prim. 2015, 1, 57-70. [CrossRef]

2. Tarraf, H.; Aydin, O.; Mungan, D.; Albader, M.; Mahboub, B.; Doble, A.; Lahlou, A.; Tariq, L.; Aziz, F.; El Hasnaoui, A. Prevalence of asthma among the adult general population of five Middle Eastern countries: Results of the SNAPSHOT program. BMC Pulm. Med. 2018, 18, 68. [CrossRef] [PubMed]

3. Global Initiative for Asthma. Global Strategy for Asthma Management and Prevention. 2021. Available online: https://ginasthma. org/ (accessed on 15 December 2021).

4. Global Asthma Network. The Global Asthma Report 2018; Global Asthma Network: Auckland, New Zealand, 2018; ISBN 9780473465230 .

5. Huo, Y.; Zhang, H.Y. Genetic mechanisms of asthma and the implications for drug repositioning. Genes 2018, 9, 237. [CrossRef]

6. Miller, S.M.; Ortega, V.E. Pharmacogenetics and the development of personalized approaches for combination therapy in asthma. Curr. Allergy Asthma Rep. 2013, 13, 443-452. [CrossRef]

7. Slager, R.E.; Hawkins, G.A.; Li, X.; Postma, D.S.; Meyers, D.A.; Bleecker, E.R. Genetics of Asthma Susceptibility and Severity. Clin. Chest Med. 2012, 33, 431-443. [CrossRef]

8. Moore, W.C.; Meyers, D.A.; Wenzel, S.E.; Teague, W.G.; Li, H.; Li, X.; D’Agostino, R., Jr.; Castro, M.; Curran-Everett, D.; Fitzpatrick, A.M.; et al. Identification of asthma phenotypes using cluster analysis in the severe asthma research program. Am. $J$. Respir. Crit. Care Med. 2010, 181, 315-323. [CrossRef]

9. Barnes, P.J. Drugs for asthma. Br. J. Pharmacol. 2006, 147, 297-303. [CrossRef]

10. Green, R. New therapies and management strategies in the treatment of asthma: Patient-focused developments. J. Asthma Allergy 2010, 4, 1. [CrossRef]

11. Ashburn, T.T.; Thor, K.B. Drug repositioning: Identifying and developing new uses for existing drugs. Nat. Rev. Drug Discov. 2004, 3, 673-683. [CrossRef] [PubMed]

12. Jin, G.; Wong, S.T.C. Toward better drug repositioning: Prioritizing and integrating existing methods into efficient pipelines. Drug Discov. Today 2014, 19, 637-644. [CrossRef] [PubMed]

13. Mullard, A. Drug repurposing programmes get lift off. Nat. Rev. Drug Discov. 2012, 11, 505-506. [CrossRef]

14. Shoaib, M.; Kamal, M.A.; Danish Rizvi, S.M. Repurposed Drugs as Potential Therapeutic Candidates for the Management of Alzheimer's Disease. Curr. Drug Metab. 2017, 18, 842-852. [CrossRef]

15. Sertkaya, A.; Birkenbach, A.; Berlind, A.; Euraud, J. Examination of clinical trials costs and barriers for drug development. In US Department of Health and Human Services, Office of the Assistant Secretary for Planning and Evaluation Report; U.S. Department of Health and Human Services: Washington, DC, USA, 2014; pp. 1-92.

16. Turanli, B.; Grøtli, M.; Boren, J.; Nielsen, J.; Uhlen, M.; Arga, K.Y.; Mardinoglu, A. Drug repositioning for effective prostate cancer treatment. Front. Physiol. 2018, 9, 500. [CrossRef] [PubMed]

17. Buniello, A.; Macarthur, J.A.L.; Cerezo, M.; Harris, L.W.; Hayhurst, J.; Malangone, C.; McMahon, A.; Morales, J.; Mountjoy, E.; Sollis, E.; et al. The NHGRI-EBI GWAS Catalog of published genome-wide association studies, targeted arrays and summary statistics 2019. Nucleic Acids Res. 2019, 47, D1005-D1012. [CrossRef] [PubMed]

18. Denny, J.C.; Bastarache, L.; Ritchie, M.D.; Carroll, R.J.; Zink, R.; Mosley, J.D.; Field, J.R.; Pulley, J.M.; Ramirez, A.H.; Bowton, E.; et al. Systematic comparison of phenome-wide association study of electronic medical record data and genome-wide association study data. Nat. Biotechnol. 2013, 31, 1102-1110. [CrossRef] [PubMed]

19. Lau, A.; So, H.C. Turning genome-wide association study findings into opportunities for drug repositioning. Comput. Struct. Biotechnol. J. 2020, 18, 1639-1650. [CrossRef] [PubMed]

20. Ward, L.D.; Kellis, M. HaploReg v4: Systematic mining of putative causal variants, cell types, regulators and target genes for human complex traits and disease. Nucleic Acids Res. 2016, 44, D877-D881. [CrossRef] [PubMed]

21. Wishart, D.S.; Feunang, Y.D.; Guo, A.C.; Lo, E.J.; Marcu, A.; Grant, J.R.; Sajed, T.; Johnson, D.; Li, C.; Sayeeda, Z.; et al. DrugBank 5.0: A major update to the DrugBank database for 2018. Nucleic Acids Res. 2018, 46, D1074-D1082. [CrossRef] [PubMed]

22. Okada, Y.; Wu, D.; Trynka, G.; Raj, T.; Terao, C.; Ikari, K.; Kochi, Y.; Ohmura, K.; Suzuki, A.; Yoshida, S.; et al. Genetics of rheumatoid arthritis contributes to biology and drug discovery. Nature 2013, 506, 376-381. [CrossRef] [PubMed]

23. Liao, Y.; Wang, J.; Jaehnig, E.J.; Shi, Z.; Zhang, B. WebGestalt 2019: Gene set analysis toolkit with revamped UIs and APIs. Nucleic Acids Res. 2019, 47, W199-W205. [CrossRef] [PubMed]

24. Zhbannikov, I.Y.; Arbeev, K.; Yashin, A.I. Package 'haploR'. Available online: https://cran.r-project.org/web/packages/haploR/ index.html (accessed on 10 September 2021).

25. Wang, J.; Liao, Y.; Jaehnig, E.; Shi, Z.; Sheng, Q. Package 'WebGestaltR'. Available online: https://cran.r-project.org/web/ packages/WebGestaltR/index.html (accessed on 10 September 2021)

26. Jevnikar, Z.; Östling, J.; Ax, E.; Calvén, J.; Thörn, K.; Israelsson, E.; Öberg, L.; Singhania, A.; Lau, L.C.K.; Wilson, S.J.; et al. Epithelial IL-6 trans-signaling defines a new asthma phenotype with increased airway inflammation. J. Allergy Clin. Immunol. 2010, 143, 577-590. [CrossRef]

27. Akira, S. IL-6-regulated transcription factors. Int. J. Biochem. Cell Biol. 1997, 29, 1401-1418. [CrossRef]

28. Akira, S.; Nishio, Y.; Inoue, M.; Wang, X.J.; We, S.; Matsusaka, T.; Yoshida, K.; Sudo, T.; Naruto, M.; Kishimoto, T. Molecular cloning of APRF, a novel IFN-stimulated gene factor 3 p91-related transcription factor involved in the gp130-mediated signaling pathway. Cell 1994, 77, 63-71. [CrossRef] 
29. Akira, S.; Kishimoto, T. IL-6 and NF-IL6 in Acute-Phase Response and Viral Infection. Immunol. Rev. 1992, 127, 25-50. [CrossRef]

30. Pelaia, G.; Gallelli, L.; D'Agostino, B.; Vatrella, A.; Cuda, G.; Fratto, D.; Renda, T.; Galderisi, U.; Piegari, E.; Crimi, N.; et al. Effects of TGF- $\beta$ and Glucocorticoids on Map Kinase Phosphorylation, IL-6/IL-11 Secretion and Cell Proliferation in Primary Cultures of Human Lung Fibroblasts. J. Cell. Physiol. 2006, 211, 736-747. [CrossRef]

31. Rincon, M.; Irvin, C.G. Role of IL-6 in asthma and other inflammatory pulmonary diseases. Int. J. Biol. Sci. 2012, 8, 1281-1290. [CrossRef] [PubMed]

32. Ullah, M.A.; Revez, J.A.; Loh, Z.; Simpson, J.; Zhang, V.; Bain, L.; Varelias, A.; Rose-John, S.; Blumenthal, A.; Smyth, M.J.; et al. Allergen-induced IL- 6 trans-signaling activates $\gamma \delta$ T cells to promote type 2 and type 17 airway inflammation. J. Allergy Clin. Immunol. 2015, 136, 1065-1073. [CrossRef]

33. Revez, J.A.; Bain, L.M.; Watson, R.M.; Towers, M.; Collins, T.; Killian, K.J.; O’Byrne, P.M.; Gauvreau, G.M.; Upham, J.W.; Ferreira, M.A.R. Effects of interleukin-6 receptor blockade on allergen-induced airway responses in mild asthmatics. Clin. Transl. Immunol. 2019, 8, e1044. [CrossRef] [PubMed]

34. Falcone, D.; Gallelli, L.; Di Virgilio, A.; Tucci, L.; Scaramuzzino, M.; Terracciano, R.; Pelaia, G.; Savino, R. Effects of simvastatin and rosuvastatin on RAS protein, matrix metalloproteinases and NF- $\mathrm{KB}$ in lung cancer and in normal pulmonary tissues. Cell Prolif. 2013, 46, 172-182. [CrossRef]

35. Zeki, A.A.; Elbadawi-Sidhu, M. Innovations in asthma therapy: Is there a role for inhaled statins? Expert Rev. Respir. Med. 2018, 12, 461-473. [CrossRef] [PubMed]

36. Zeki, A.A.; Franzi, L.; Last, J.; Kenyon, N.J. Simvastatin inhibits airway hyperreactivity: Implications for the mevalonate pathway and beyond. Am. J. Respir. Crit. Care Med. 2009, 180, 731-740. [CrossRef]

37. Alexeeff, S.E.; Litonjua, A.A.; Sparrow, D.; Vokonas, P.S.; Schwartz, J. Statin use reduces decline in lung function: VA Normative Aging Study. Am. J. Respir. Crit. Care Med. 2007, 176, 742-747. [CrossRef]

38. Gao, S.; Wang, C.; Li, W.; Shu, S.; Zhou, J.; Yuan, Z.; Wang, L. Allergic asthma aggravated atherosclerosis increases cholesterol biosynthesis and foam cell formation in apolipoprotein E-deficient mice. Biochem. Biophys. Res. Commun. 2019, 519, 861-867. [CrossRef] [PubMed]

39. Wu, S.; Yang, R.; Wang, G. Anti-asthmatic effect of pitavastatin through aerosol inhalation is associated with CD4+ CD25+ Foxp3+ T cells in an asthma mouse model. Sci. Rep. 2017, 7, 6084. [CrossRef] [PubMed]

40. Imamura, M.; Okunishi, K.; Ohtsu, H.; Nakagome, K.; Harada, H.; Tanaka, R.; Yamamoto, K.; Dohi, M. Pravastatin attenuates allergic airway inflammation by suppressing antigen sensitisation, interleukin 17 production and antigen presentation in the lung. Thorax 2009, 64, 44-49. [CrossRef] [PubMed]

41. Liou, C.J.; Cheng, P.Y.; Huang, W.C.; Chan, C.C.; Chen, M.C.; Kuo, M.L.; Shen, J.J. Oral lovastatin attenuates airway inflammation and mucus secretion in ovalbumin-induced murine model of asthma. Allergy Asthma Immunol. Res. 2014, 6, 548-557. [CrossRef] [PubMed]

42. Samson, K.T.R.; Minoguchi, K.; Tanaka, A.; Oda, N.; Yokoe, T.; Yamamoto, Y.; Yamamoto, M.; Ohta, S.; Adachi, M. Inhibitory effects of fluvastatin on cytokine and chemokine production by peripheral blood mononuclear cells in patients with allergic asthma. Clin. Exp. Allergy 2006, 36, 475-482. [CrossRef]

43. Wang, W.; Le, W.; Ahuja, R.; Cho, D.; Hwang, P.H.; Upadhyay, D. Inhibition of Inflammatory Mediators: Role of Statins in Airway Inflammation. Otolaryngol. Head Neck Surg. 2011, 144, 982-987. [CrossRef]

44. Liu, J.; Suh, D.; Yang, E.; Lee, S.; Park, H.; Shin, Y.S. Attenuation of airway inflammation by simvastatin and the implications for asthma treatment: Is the jury still out? Exp. Mol. Med. 2014, 46, e113. [CrossRef]

45. Polosa, R.; Holgate, S.T. Adenosine Receptors as Promising Therapeutic Targets for Drug Development in Chronic Airway Inflammation. Curr. Drug Targets 2006, 7, 699-706. [CrossRef]

46. Brown, R.A.; Spina, D.; Page, C.P. Adenosine receptors and asthma. Br. J. Pharmacol. 2008, 153, 446-456. [CrossRef] [PubMed]

47. Keane-Myers, A.M.; Gause, W.C.; Finkelman, F.D.; Xhou, X.D.; Wills-Karp, M. Development of murine allergic asthma is dependent upon B7-2 costimulation. J. Immunol. 1998, 160, 1036-1043. [PubMed]

48. Haczku, A.; Takeda, K.; Redai, I.; Hamelmann, E.; Cieslewicz, G.; Joetham, A.; Loader, J.; Lee, J.J.; Irvin, C.; Gelfand, E.W.; et al. Airway Hyperresponsiveness in Mice. Am. J. Respir. Crit. Care Med. 1999, 86, 1638-1643. [CrossRef] [PubMed]

49. Wang, T.-N.; Tseng, H.-I.; Kao, C.-C.; Chu, Y.-T.; Chen, W.-Y.; Wu, P.-F.; Lee, C.-H.; Ko, Y.-C. The effects of NOS1 gene on asthma and total IgE levels in Taiwanese children, and the interactions with environmental factors. Pediatr. Allergy Immunol. 2010, 21, 1064-1071. [CrossRef]

50. Schmalbach, T.; Fuhr, R.; Albayaty, M.; Allen, K.; Douglas, M.; Dunbar, J.; McLaughlin, J.; Alexander, L.; McKee, C. Duvelisib, a PI3K- $\delta, \gamma$ inhibitor, in subjects with mild asthma. Eur. Respir. J. 2015, 46, PA2122.

51. Mishra, G. Serious adverse effects of anticancer drugs-A review. Ideal Res. 2018, 3.

52. Fetro, C.; Scherman, D. Drug repurposing in rare diseases: Myths and reality. Therapies 2020, 75, 157-160. [CrossRef]

53. Brightling, C.E.; Nair, P.; Cousins, D.J.; Louis, R.; Singh, D. Risankizumab in Severe Asthma-A Phase 2a, Placebo-Controlled Trial. N. Engl. J. Med. 2021, 385, 1669-1679. [CrossRef] 